\title{
FUZZY-MULTIPLE MODELS OF FORMALIZATION OF SOIL RESOURCES IN FORMATION OF SYSTEM FOR CONTROLLING PROCESSES OF FEED PRODUCTION FROM GRASSES
}

\author{
Vladimir Popov ${ }^{1}$, Aleksandr Spesivtsev ${ }^{2}$, Alexey Sukhoparov ${ }^{1}$, Vasiliy Spesivtsev ${ }^{1}$ \\ ${ }^{1}$ Institute for Engineering and Environmental Problems in Agricultural Production, Russia; \\ ${ }^{2}$ Saint-Petersburg Institute for Informatics and Automation of RAS, Russia \\ popov_vd@mail.ru,sav2050@gmail.com, sukhoparov_ai@mail.ru,ryukuro@yandex.ru
}

\begin{abstract}
The technological process of grass feed production is considered as a complex system. From a mathematical point of view, all agricultural processes of the system are classified as difficult to formalize. Previous studies have shown that an effective model for controlling the technological process of grass feed production is a synthesis of a semantic object-oriented network, in the nodes of which mathematical models are located. This approach is natural, since it takes into account all the links in the technological chain, as well as imposed controlled (for example, agrotechnical periods) and uncontrolled (weather and climate) impacts on the system as a whole. In such business conditions, instead of the traditional deterministic modeling methods, the expert knowledge of highly qualified specialists is usually used. The method of constructing fuzzy-probabilistic models developed and confirmed in practice is increasingly used in agricultural production. This is due, first of all, to the fact that the modeling process on the basis of explicit and implicit expert knowledge does not require knowledge of special mathematical methods from workers. The whole process of building models is conducted in the professional language of experts. Moreover, the expert is used as an "intelligent measuring and diagnostic system". The previously obtained metamodel as a model of the first stage of the hierarchy included five variables: soil resources, feed production, technological resource, material and technical base, weather and climate conditions. Only the technological resource was considered in detail, for which at the second level of the hierarchy a model was constructed according to six variables and then the variable "preservative application" is also represented by six variables of the third stage of the hierarchical model. This study presents fuzzy-possible models representing the branch of the semantic network in the variable "soil resources" of the original metamodel for controlling the entire technological chain of feed production. It is shown that the obtained models adequately represent the knowledge of experts on the tasks to be solved of a common problem - the construction of a control model for the technological process of the production of feed from herbs.
\end{abstract}

Keywords: grass feed, knowledge formalization, fuzzy-feasibility models.

\section{Introduction}

Agricultural processes and production are multidisciplinary. However, the description of them by deterministic methods is difficult due to the existing uncertainty and the lack of effective methods of transmitting information. The number of researchers is limited by the minimum number of models available. So, in [1], the models obtained describe the dynamics of soil water, the transfer of nitrates and ammonia, the development of crop growth and grain productivity with various methods of crop rotation and fertilizer management. For all the information content of the adequate information received, there is no generalized indicator of the results obtained.

Nevertheless, significant assistance in decision-making is provided by obtaining data on the influence of individual factors on the phenomenon under study. So, when studying the loss of humus [2], several methods have been proposed to return soil organic matter with quantitative estimates. Such data play a significant role in model building.

To model grassland communities, a dynamic model was created [3], which includes a set of rules for simulating obvious seasonal changes in the species composition of managed pastures with various soil, climatic, and administrative factors. The results show, according to the authors, that pasture modeling without taking into account the dynamics of plant diversity distorts forecasts of future feed production and estimates of animal feed reserves.

The problem of generalizing information in some way concerns research [4] on the development of an agricultural land detector to determine a suitable plant using Raspberry-Pi. However, the algorithm for summarizing data from primary detectors is not disclosed, and therefore, it is not possible to evaluate the adequacy of the applied method of convolution of information.

In the article [5], it was shown that the development of new modeling technologies should facilitate timely, quantitative information for a better understanding of the interaction of soil-pasture- 
animals and animal management in pasture systems. Models of global positioning technology, improved dietary markers, near-infrared spectroscopy, are improved tools for making knowledgebased decisions about the productivity limits of grazing animals.

It should be noted that, firstly, due to the lack of effective mathematical methods for convolving multifactor information, in most cases the decision remains solely with the person, and secondly, modeling is considered as some generalization of experimental statistical material by acceptable methods. This practice is generally accepted not only in agriculture.

This study is aimed at creating mathematical models, using the knowledge and experience of experts, based on a fuzzy-probabilistic approach [6]. With this approach, the role of the expert increases significantly, since his knowledge can be represented in a multifactorial space with an analytical expression, and the statistical material serves to verify the adequacy of the constructed model.

The fuzzy-probabilistic approach is not an alternative to statistical or other well-known methods, but serves as a researcher for expanding the possibilities of using mathematical devices in the conditions of uncertainties inherent in multifactor agricultural production.

\section{Materials and methods}

The fuzzy-possible approach is a synthesis of the theory of experimental design and elements of the theory of fuzzy sets [6], which allows the translation of fuzzy information (which is typical of the expert level) into quantitative, i.e. to formalize the experience of an expert (group of experts) in the form of mathematical models, on the basis of which it is possible to control the studied technological process. The sequence of actions to extract and formalize expert knowledge in agriculture is presented in [7]. For this, it is advisable, as mentioned above, to systematically extract and formalize expert information in the form of mathematical polynomial models based on a fuzzy-possible approach.

Previous studies [7] showed that the production of animal feed from grasses is a complex multicomponent and multicriteria problem and their solution should be approached systematically. In addition, the information received from an expert specialist is most often verbal, then the most appropriate method for taking into account the variety of factors into a single formalized model is a fuzzy-possible approach using expert knowledge and experience.

This approach is already becoming a common decision-making technique in agricultural practice. So, in [7], a metamodel for assessing the effectiveness of the technological process for the production of feed from grasses according to the five most important criteria for agricultural activity is presented: $X_{1}$ - economic criterion; $X_{2}$ - energy criterion; $X_{3}$ - environmental criterion; $X_{4}$ - criterion for balanced diets; $X_{5}$ - criterion of potential forage land.

Polynomial metamodel of the cumulative effect of the criteria of the technological process of grass feed production in the following form:

$$
\begin{aligned}
& Y=0.523+0.014 x_{1}+0.039 x_{2}+0.02 x_{3}+0.033 x_{4}+0.067 x_{5}-0.014 x_{1} x_{4}-0.011 x_{2} x_{5}+ \\
& +0.008 x_{3} x_{5}-0.017 x_{4} x_{5}
\end{aligned}
$$

In model (1) all variables are presented in standardized scale according to the formula

$$
x_{i}=\frac{X_{i}-X_{i}^{\mathrm{cp}}}{\Delta \mathrm{X}_{\mathrm{i}}},
$$

where $X_{i}$ - measured estimate of the relevant variable;

$X^{c p}{ }_{i}$ - average value of the variable measurement interval;

$\Delta X_{i}$ - interval of variation.

Judging by the magnitude of the coefficients for the linear terms of the model (1), the most significant criterion for evaluating the efficiency of feed production from grasses is the criterion for using the potential of fodder land $X_{5}$ and only then the weight of the energy character $X_{2}$ and the balance of diets $X_{4}$ are almost two times lower. The least weighty is the criterion of economic character $X_{1}$, although such an unexpected conclusion is quite logical. So, for example, with the high 
potential of forage lands $X_{5}$, it is quite natural to reduce the cost of feed, and they make up about $70 \%$ of the cost of livestock products.

This study solves the problem of identifying and using the potential of soil resources as fodder land regardless of the economy, which should contribute to the development of rational technical and technological solutions in the process of cultivating grasses on various types of soils.

The soil resource at a specific site $(Y)$ is formed under the influence of a number of indicators:

- $X_{1}$ - agrotechnical characteristics of soils, qualitative variable;

- $X_{2}$ - soil acidity, $\mathrm{pH}$;

- $X_{3}$ - humus content, \%;

- $X_{4}$ - saturation with minerals, \%;

- $X_{5}$ - soil moisture content, \%;

- $X_{6}$ - predecessor cultivated in this area to grass culture, quality variable;

- $Y$ - generalized indicator of the soil resource of fodder land, a qualitative variable. Moreover, $Y$ is considered as a possible achievement of the use of its full potential.

Variables $X_{1}-X_{6}$ are different in physical nature and are determined not only by quantitative quantities, but also verbal ones, which cannot be uniquely determined. These variables are characterized by multitude of information flows of various purposes with different levels of discreteness, reliability, accuracy, and other metrological characteristics, which complicates the description and quantification of the soil resource.

Therefore, according to the fuzzy-possible approach, using expert knowledge and experience in agriculture [1-3], it is advisable to express the selected factor space in the form of linguistic variables. Figure 1 shows an example of representing a generalized indicator of the soil resource of forage land as a linguistic variable.

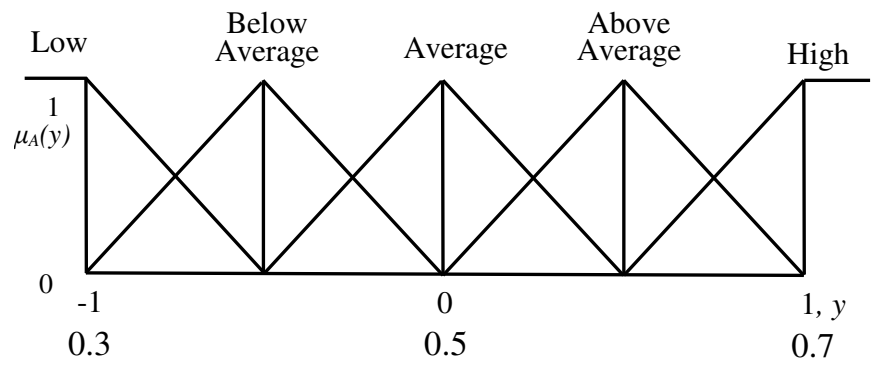

Fig. 1. $Y$ as a linguistic variable

It is advisable to extract expert knowledge in order to further formalize it through special questionnaires, in which the expert assesses the impact of each variable on the output indicator at a verbal level. The construction of optimal survey plans was carried out on the basis of the theory of experimental design. The questionnaire of experts with an assessment of the degree of influence of the variables forming the soil resource with their extreme values (characteristic of the North-West of Russia) determining the assessment of this resource of forage land is presented in Table 1.

The expert values translated into a numerical measure, after corresponding processing on a PC in the Microsoft Office Excel program filled out by a specialist in questionnaire Table 1 (the last column), made it possible to obtain an expression of the soil resource of lumpy lands taking into account the degree of influence of the factors that form the soil resource.

$$
\begin{aligned}
& Y=0.434+0.051 X_{1+} 0.016 X_{2}+0.066 X_{3}+0.059 X_{4}+0.051 X_{5}+0.016 X_{6}-0.016 X_{1} X_{3} \\
& +0.016 X_{1} X_{4}-0.012 X_{2} X_{3}+0.012 X_{2} X_{4}-0.016 X_{3} X_{4}+0.031 X_{4} X_{5},
\end{aligned}
$$

where all variables are presented in a standardized scale by the formula (2).

Analysing the polynomial model (3), we can conclude that the greatest influence on the formation of the soil resource of forage lands is exerted by the content of humus $\left(X_{3}\right)$ and the content of minerals in the soil $\left(X_{4}\right)$. An important role is also played by the agrotechnical characteristics of the soil $\left(X_{1}\right)$ and directly the moisture content of the soil $\left(X_{5}\right)$, as well as the combined effect of the content of 
minerals and moisture in the soil $\left(X_{4} X_{5}\right)$. Thus, by introducing minerals into the soil and land reclamation, it is possible to significantly increase the potential of soil resources when cultivating perennial grasses for animal feed, and not only carrying out crop rotation and liming the soil.

Table 1

Fragment of the survey matrix with expert estimates and model calculations

\begin{tabular}{|c|c|c|c|c|c|c|c|c|c|}
\hline \multirow{2}{*}{ No. } & $\begin{array}{c}\text { Agro- } \\
\text { technical } \\
\text { characterist } \\
\text { ics of the } \\
\text { soil }\end{array}$ & Acid & ity & Humus & $\begin{array}{c}\text { Saturation } \\
\text { with } \\
\text { mineral } \\
\text { fertilizers }\end{array}$ & $\begin{array}{c}\text { Moisture } \\
\text { content of } \\
\text { the soil }\end{array}$ & $\begin{array}{c}\text { Pre- } \\
\text { cursor }\end{array}$ & \multicolumn{3}{|c|}{ Soil resource $\boldsymbol{Y}$} \\
\cline { 2 - 11 } & $x_{1}$ & $x_{2}$ & $x_{3}$ & $x_{4}$ & $x_{5}$ & $x_{6}$ & \multicolumn{2}{|c|}{ Expert } & Calc. \\
\hline 1 & -1 & -1 & -1 & -1 & -1 & -1 & L & 0.2 & 0.192 \\
\hline 2 & 1 & -1 & -1 & -1 & -1 & 1 & BA & 0.325 & 0.325 \\
\hline$\ldots$ & $\ldots$ & $\ldots$ & $\ldots$ & $\ldots$ & $\ldots$ & $\ldots$ & $\ldots$ & $\ldots$ & $\ldots$ \\
\hline 30 & 1 & -1 & 1 & 1 & 1 & -1 & AA-H & 0.6375 & 0.645 \\
\hline 31 & -1 & 1 & 1 & 1 & 1 & -1 & A-AA & 0.575 & 0.575 \\
\hline 32 & 1 & 1 & 1 & 1 & 1 & 1 & H & 0.7 & 0.708 \\
\hline
\end{tabular}

\section{Discussion and Results}

The results of the expert assessment of the state of soil resource use according to model (3) in the farms of the Leningrad Region are shown in Table 2, where the values of the variables are given in a standardized scale.

Table 2

\section{Assessment of soil resource}

\begin{tabular}{|c|c|c|c|c|c|c|c|c|}
\hline Household & $\begin{array}{c}\text { Agro- } \\
\text { technical } \\
\text { character- } \\
\text { istics of } \\
\text { the soil }\end{array}$ & Acidity & Humus & $\begin{array}{c}\text { Saturation } \\
\text { with } \\
\text { mineral } \\
\text { fertilizers }\end{array}$ & $\begin{array}{c}\text { Moisture } \\
\text { content } \\
\text { of the } \\
\text { soil }\end{array}$ & $\begin{array}{c}\text { Pre- } \\
\text { cursor }\end{array}$ & \multicolumn{2}{|c|}{ Soil resource $\boldsymbol{Y}$} \\
\cline { 2 - 9 } & $x_{1}$ & $x_{2}$ & $x_{3}$ & $x_{4}$ & $x_{5}$ & $x_{6}$ & Calc. & Expert \\
\hline $\begin{array}{c}\text { FSBI } \\
\text { "Kalozhitsy" } \\
\text { Volosovsky }\end{array}$ & 0.5 & 0.6 & 0.5 & 0.8 & 0.3 & 1 & 0.586 & AA \\
\hline $\begin{array}{c}\text { Rassvet OJSC } \\
\text { Luga district }\end{array}$ & 0 & 0.1 & 0.2 & 0.3 & 0.1 & 0 & 0.471 & A \\
\hline $\begin{array}{c}\text { Andreevskoye } \\
\text { Tikhvindstr. }\end{array}$ & -0.5 & -0.6 & -0.4 & -0.5 & 0.2 & -0.5 & 0.340 & L-BA \\
\hline
\end{tabular}

As follows from the calculations in Table. 2, the efficiency of using the soil resource in the FSBI Kalozhytsy, according to the scale of Figure 1, is close to the term of the aircraft, i.e. to use the full potential of soil resources, while Rassvet OJSC is closer to C, and the Andreevskoye farm is closer to L-BA, where the potential of soil resources is very low due to the low application of mineral fertilizers, lack of liming and land reclamation.

\section{Conclusions}

An adequate fuzzy-probabilistic six-factor model of the second level is constructed as a generalized indicator of the soil resource of forage land. Moreover, $Y$ is considered as a possible achievement of using its potential, when taking into account the interaction of all variables of the factor space. The soil resource of the land plot plays a decisive role in the initial semantic network of the metamodel of managing the entire technological chain of forage production from grasses. At the same time, a synergistic effect is achieved from the combined influence of factors: quantitative 
estimates of the constituent indicators of soil potential (coefficients for variables) and their combined effect on farms (generalized indicator) allow quantifying the measure of their possible qualitative improvement at the level of this agroclimatic zone, as well as from the application of specific technical and technological solutions involving operations on tillage, fertilizing, reclamation or irrigation, liming measures, etc.

\section{References}

[1] Liang H., Hu K., Batchelor W.D., Qi Z., Li B. An integrated soil-crop system model for water and nitrogen management in North China. Sci Rep6, 25755, 2016.

[2] Rusu A.L., Plămădeală V. Rationale for Maintaining Humus in Arable Soils of Moldova Evolution of chernozem_1, pp. 365-372.

[3] Movedi E., Bellocchi G., Argenti G., Paleari L., Vesely F., Stagliano N., Dibari C., Confalonieri R. Development of generic crop models for simulation of multi-species plant communities in mowngrasslands, Ecological Modelling, 401, pp.111-128.

[4] Junfitrhana A.P., Langlangbuana M.L., Fatah W.A., Susilawati. Developing potential agriculture land detector for determine suitable plant using Raspberry-Pi. 2017 International Conference on Computing Engineering and Design (ICCED), 2017, pp. 1-4.

[5] Boval M., Dixon R. M. The importance of grasslands for animal production and other func-tions: a review on management and methodological progress in the tropics, Animal, 6 (5), pp. 748-762.

[6] Игнатьев М.Б. Марлей В.Е., Михайлов В.В., Спесивцев А.В. Моделирование слабоформализованных систем на основе явных и неявных экспертных знаний (Modeling weakly formalized systems based on explicit and implicit expert knowledge) СПб: ПОЛИТЕХПРЕСС, 2018. - 430 c. (In Russian).

[7] Popov, V.D., Spesivtsev, A.V., Sukhoparov, A.I., Spesivtsev, V.A. Use of logical-linguistic models to predict the retained biological potential of grasses during their conservation. Proceedings of the 19th International Conference on Soft Computing and Measurements, SCM 2016. Russia, June 22-24, 2016, Revised Selected Papers, 2016, pp. 244-246. 